Contents list available at IJRED website

Int. Journal of Renewable Energy Development (IJRED)

Journal homepage: http://ejournal.undip.ac.id/index.php/ijred

\title{
Premixed Combustion of Coconut Oil on Perforated Burner
}

\author{
I.K.G. Wirawana, ${ }^{a *}$, I.N.G. Wardanab, Rudy Soenoko ${ }^{\mathrm{b}}$, Slamet Wahyudi ${ }^{\mathrm{b}}$ \\ a Mechanical Engineering Department, Udayana University, Bali, INDONESIA \\ ${ }^{\mathrm{b}}$ Mechanical Engineering Department, Brawijaya University, East Java, INDONESIA
}

\section{Article history:}

Received July 21, 2013 Received in revised form Sept. 15, 2013 Accepted Oct 2, 2013 Available online

\begin{abstract}
Coconut oil premixed combustion behavior has been studied experimentally on perforated burner with equivalence ratio $(\varphi)$ varied from very lean until very rich. The results showed that burning of glycerol needs large number of air so that the laminar burning velocity $\left(\mathrm{S}_{\mathrm{L}}\right)$ is the highest at very lean mixture and the flame is in the form of individual Bunsen flame on each of the perforated plate hole. As $\varphi$ is increased the $S_{\mathrm{L}}$ decreases and the secondary Bunsen flame with open tip occurs from $\varphi=0.54$ at the downstream of perforated flame. The perforated flame disappears at $\varphi=0.66$ while the secondary Bunsen flame still exist with $\mathrm{S}_{\mathrm{L}}$ increases following that of hexadecane flame trend and then extinct when the equivalence ratio reaches one or more. Surrounding ambient air intervention makes $S_{\mathrm{L}}$ decreases, shifts lower flammability limit into richer mixture, and performs triple and cellular flames. The glycerol diffusion flame radiation burned fatty acids that perform cellular islands on perforated hole. Without glycerol, laminar flame velocity becomes higher and more stable as perforated flame at higher $\varphi$. At rich mixture the Bunsen flame becomes unstable and performs petal cellular around the cone flame front.
\end{abstract}

Keywords: cellular flame, glycerol, perforated flame, secondary Bunsen flame with open tip, triple flame

\section{Introduction}

Large number of coconut is available in Indonesia that grows in the lowlands near beach about 81,000 kilometers long. Coconut oil has the shortest carbon chain in vegetable oils group (Yuan et al. 2005) and it has similar chemical structure with petro diesel. Thus, coconut oil is suitable for Diesel engine. So far, coconut oil is used as non-premixed fuel, for example in pressure stove (Kratzeisen \& Müller 2010) because of its lower exhaust emissions, more environmental friendly, lower calorific value compared to diesel (Machacon et al. 2001; Suresh et al. 2009; Singh et al. 2010; Alamu et al. 2010).

However, coconut oil still cannot be applied directly as non-premixed in diesel engine because of several disadvantages such as high viscosity, low volatility, composed mostly by unsaturated long-chain fatty acid with low reactivity, preheating necessity, atomization and particle emissions (Recep et al. 2001;
Ayhan 2009). It would be very useful if the coconut oil can be burned in premixed flame. In that case, the oil must be vaporized before injection into combustion chamber.

The disadvantages of coconut oil are also caused by its multi-component which consists of various fatty acids with different properties and glycerol which is highly hygroscopic (Benjapornkulaphong et al. 2009). These complicate the premixed flame behavior and, therefore, intensive studies are needed.

Several studies had been conducted with various fuel compositions. The behavior of premixed flame extinction and the laminar burning velocity had been widely investigated on multi-component fuel in experimental and numerical study (Qiao et al. 2010). Liquid petroleum gas fuel was used to investigate cellular flame formation under the effect of thermal diffusivity instability and laminar flame speed at different equivalence ratio (Abdulwahid et al. 2009). Liquid petroleum gas fuel had the composition of $40 \%$

\footnotetext{
* Corresponding author:

E-mail: wirawan_ikg@yahoo.com
} 
propane $\left(\mathrm{C}_{3} \mathrm{H}_{8}\right)$ and $60 \%$ butane $\left(\mathrm{C}_{4} \mathrm{H}_{10}\right)$ with oxidizer is environment air. The study which aims to clarify the laminar burning velocity, Markstein length, and cell formation had been conducted (Vu et al. 2011). The effects of Lewis number on the burning intensity of Bunsen flame had been investigated (Mizomoto \& Yoshida 1987).

This paper discusses the premixed flame behavior of multi-component vegetable oil composed by fatty acids and glycerol. The analysis is stressed on laminar burning velocity of perforated flame and secondary Bunsen flame-open tip, cellular and triple flame which provide wider theoretical benefits in premixed combustion of vegetable oil.

\section{Experiments}

The experimental study on premixed combustion of coconut oil was carried out in an experimental apparatus shown schematically in Fig.1. The coconut oil was evaporated in a boiler with steam temperature kept constant at $160^{\circ} \mathrm{C}$. The oil steam from boiler was mixed with air from compressor at mixing chamber with equivalent ratio $(\varphi)$ varied from lean $(\varphi=0.45)$ to rich mixture $(\varphi=1.75)$. Lean mixture is range below $\varphi=0.90$ and rich is above 1.14 while nearly stoichiometric is between $\varphi=0.90$ to 1.14 . The reactant then flows into nozzle before it was ignited to form premixed flame at perforated plate installed on the top of the nozzle.

The perforated plated was installed to utilize thermal contact resistant for preserving temperature distribution which is more uniform in entire surface of the plate and ensure the uniformity flow for coconut oil with air during the combustion process. Perforated plate was made from steel and designed with geometrical matrix with 19 holes. The diameter of each hole was $2.5 \mathrm{~mm}$ and the distance between holes was $3.75 \mathrm{~mm}$.

The flame image was captured by camera in four experimental conditions: (1) premixed flame of coconut oil in contact with surrounding ambient air, (2) premixed flame of coconut oil shielded from surrounding ambient air, (3) premixed flame of coconut oil without glycerol in contact with surrounding ambient air, and (4) premixed flame of coconut oil without glycerol shielded from surrounding ambient air.

The coconut oil used in this experiment consists of $85 \%$ fatty acid and 15\% glycerol. The component of fatty acids in coconut oil is listed in Table 1. Most of the components are saturated medium-chain fatty acids. Only less than $10 \%$ are unsaturated long-chain with spontaneous combustion characteristics.

The reaction of coconut oil with the oxidizer was estimated by simple molar analysis described with equation 1 and equation 2 as follows:

$$
\begin{gathered}
\mathrm{C}_{13.26} \mathrm{H}_{26.52} \mathrm{O}_{2}+18.89\left(\mathrm{O}_{2}+3.76 \mathrm{~N}_{2}\right) \rightarrow \\
13.26 \mathrm{CO}_{2}+13.26 \mathrm{H}_{2} \mathrm{O}+71.03 \mathrm{~N}_{2} \\
\mathrm{C}_{3} \mathrm{H}_{5}(\mathrm{OH})_{3}+3.5\left(\mathrm{O}_{2}+3.76 \mathrm{~N}_{2}\right) \rightarrow \\
3 \mathrm{CO}_{2}+4 \mathrm{H}_{2} \mathrm{O}+13.16 \mathrm{~N}_{2}
\end{gathered}
$$

The equation 1 is the combustion reaction of equivalent fatty acids molecule from present data in table 1 and equation 2 is that of glycerol. From equation 1 and 2 the stoichiometric air fuel ratio (AFR stoic $)$ of coconut oil was 10.91 gram air/ gram fuel. In coconut oil without glycerol the $\mathrm{AFR}_{\text {stoic }}$ was 11.91 gram air/ gram fuel. The equivalent ratio $(\varphi)$ was calculated as the ratio of stoichiometric air fuel ratio and actual air fuel ratio.

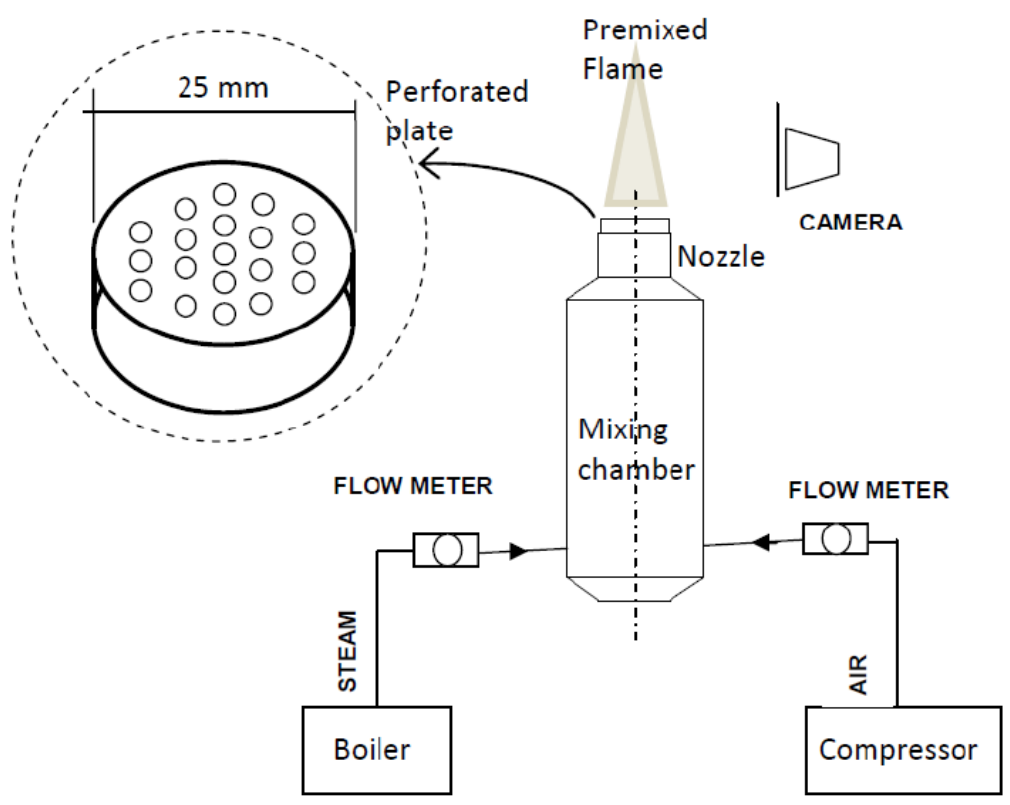

Fig. 1 Experimental apparatus 
Table 1

Coconut oil composition from many references

\begin{tabular}{|c|c|c|c|c|c|c|}
\hline \multirow{2}{*}{ Fatty acid } & \multicolumn{6}{|c|}{$\%(w / w)$} \\
\hline & $\begin{array}{l}\text { Present } \\
\text { Data }\end{array}$ & $\begin{array}{c}\text { Kumar et al. } \\
2010\end{array}$ & $\begin{array}{c}\text { Bouaid et al. } \\
2010\end{array}$ & $\begin{array}{c}\text { Satyanarayana } \\
\text { et al. } 2011\end{array}$ & $\begin{array}{c}\text { Llamas et al. } \\
2012\end{array}$ & $\begin{array}{c}\text { Palash et al. } \\
2013\end{array}$ \\
\hline Caproic (C6:0) & 0.240 & - & - & - & - & - \\
\hline Caprylic (C8:0) & 4.852 & 8.86 & 6.05 & - & 8.30 & - \\
\hline Capric (C10:0) & 5.031 & 6.17 & 4.25 & - & 3.00 & - \\
\hline Lauric (C12:0) & 46.256 & 48.83 & 49.70 & 46.50 & 55.50 & 45.60 \\
\hline Myristic (14:0) & 20.508 & 19.97 & 19.30 & 19.20 & 14.90 & 22.10 \\
\hline Palmitic (16:0) & 10.706 & 7.84 & 11.10 & 9.80 & 6.40 & 10.20 \\
\hline Stearic (18:0) & 3.711 & 3.06 & 6.55 & 3.00 & 2.50 & 3.60 \\
\hline Arachidic (20:0) & 0.051 & - & - & - & - & - \\
\hline Behenic (22:0) & 0.028 & - & - & - & - & - \\
\hline Palmitolic (16:1) & 0.018 & - & - & - & - & - \\
\hline Oleic (18:1) & 8.413 & 4.44 & 2.90 & 6.90 & 7.50 & 8.20 \\
\hline Linoleic (18:2) & 0.060 & 0.76 & - & 2.20 & 1.90 & 2.70 \\
\hline Linolenic (18:3) & 0.107 & - & - & - & - & - \\
\hline Eicosatrienoic (20:3) & 0.020 & - & - & - & - & - \\
\hline
\end{tabular}

\section{Result and Discussion}

The flame behavior at various equivalent ratios is presented in Fig. 2 to Fig.6. Fig. 2 shows premixed flame of coconut oil with glycerol. Glycerol is intensively burned at $\varphi$ from 0.93 until 1.14 (Wardana 2010), which is within stoichiometry. At rich mixture $(\varphi=$ 1.61) the amount of glycerol burned is reduced because being far from the stoichiometry. It is shown from the top view in Fig. 3 that there are two flames structure: perforated Bunsen flame with secondary Bunsen opentip flame at lean mixture (Fig. 3a) and triple flame with cellular flame at very rich mixtures (Fig. 3b).

When flame of coconut oil with glycerol was isolated from surrounding ambient air as shown in Fig. 4, perforated Bunsen flame takes place at $\varphi 0.45$ to 0.66 . From $\varphi 0.54$ to 0.80 secondary Bunsen flame with open-tip occurs at downstream of the perforated Bunsen flame. Flame tends to extinct above $\varphi=0.93$. This phenomenon indicates that coconut oil with glycerol needs large number of air or very lean mixture to perform flame so that its stability is greatly influenced by the ambient air.

The cause of cellular flame, secondary open-tip Bunsen flame, triple flame and flame extinction was elucidated by removing glycerol from the oil by hydrolysis process at a temperature of $300^{\circ} \mathrm{C}$ for 15 minutes (Alenezi et al. 2009; Wang et al. 2012). Flame of coconut oil without glycerol is shown in Fig. 5. The island cellular with triple flame which occurs at coconut oil with glycerol disappears and changes into petals cellular without triple flame at $\varphi=1.24$ while perforated flame and secondary Bunsen flame with open-tip are still present. When flame was isolated from surrounding ambient air as shown in Fig. 6, flame is stable from lean $(\varphi=0.66)$ until rich mixture $(\varphi=1.75)$. Flame of coconut oil without glycerol did not undergo extinction.

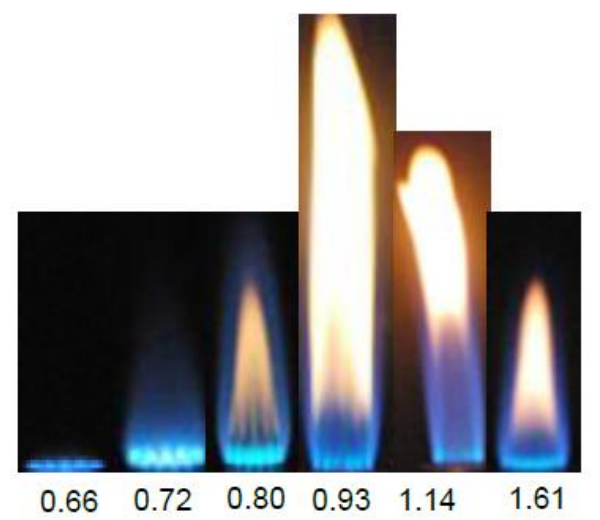

Fig. 2 Flame structure of coconut oil with glycerol

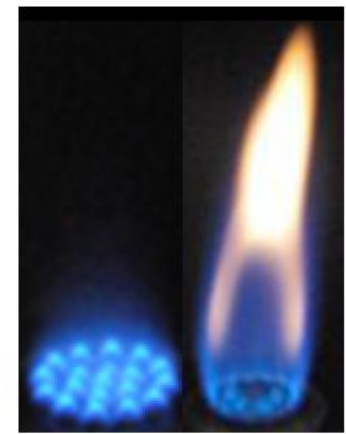

(a)

(b)

Fig. 3 Top view of: (a) perforated Bunsen flame with secondary Bunsen open tip flame, $\varphi=0.72$; (b) Triple flame with cellular flame, $\varphi=1.61$ 


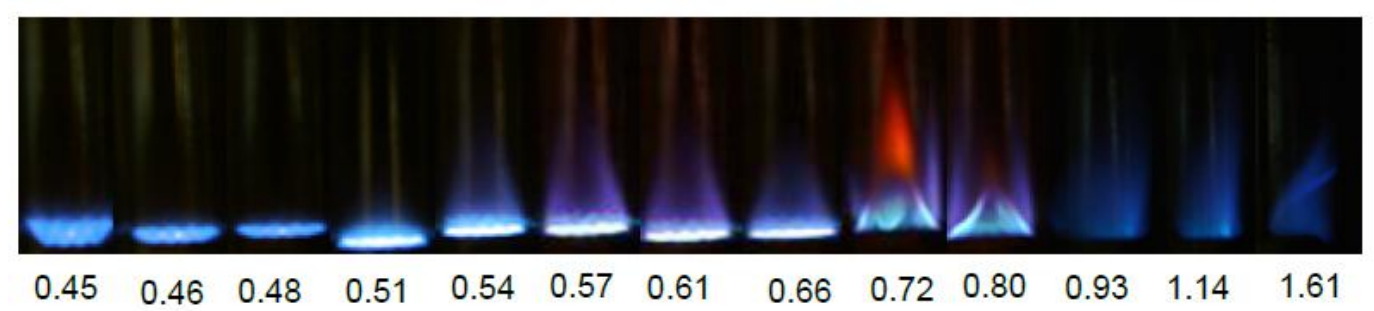

Fig. 4 Flame shapes of coconut oil with glycerol isolated from ambient air

From those data it can be concluded that coconut oil with glycerol need very large number of air to burn glycerol due to its hygroscopic properties. When the concentration of air in the reactant is low or the mixture is rich glycerol causes the formation of the triple flame, cellular flame, and the extinction. Since the open tip of Bunsen flame always takes place at coconut oil with and without glycerol, it may be caused by any mechanism which will be discussed latter on. Booth glycerol and long-chain fatty acids produce cellular flame of different types which will also be discussed afterward.

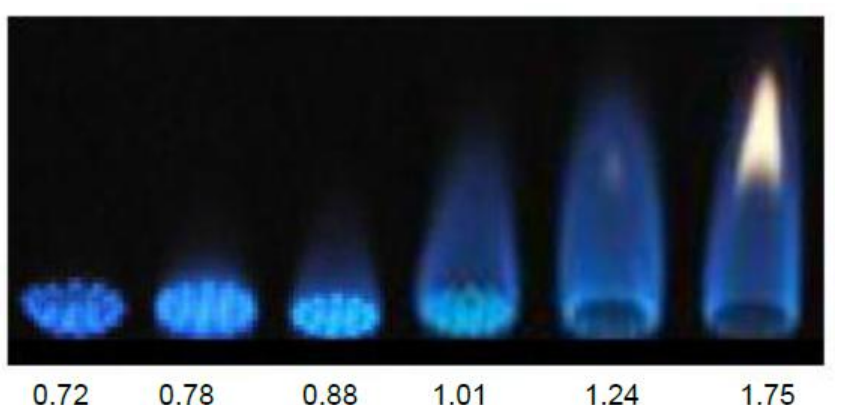

Fig. 5 Flame shape of coconut oil without glycerol

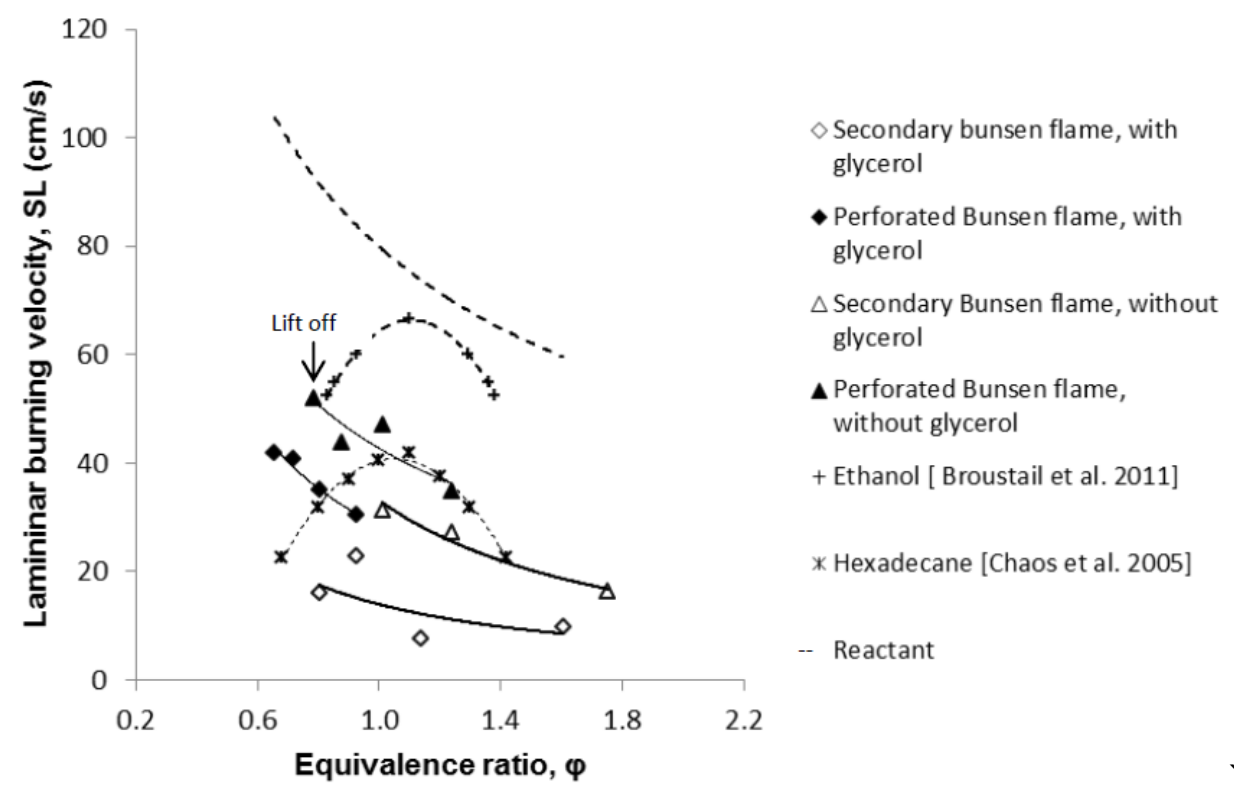

Fig. 7 Laminar burning velocity of coconut oil versus equivalence ratio
Perforated Bunsen flame, with glycerol

Secondary Bunsen flame, without

Perforated Bunsen flame,

Ethanol [ Broustail et al. 2011]

where: $\alpha$ is the half angel of the Bunsen flame cone tip.

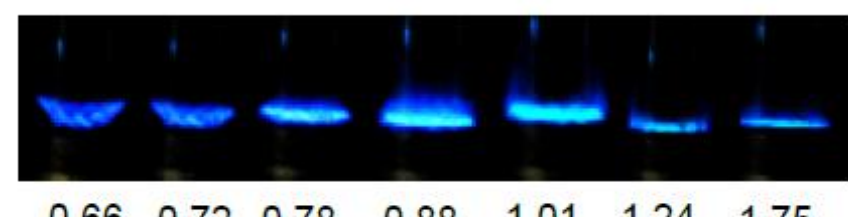

Fig. 6 Flame shapes of coconut oil without glycerol isolated from surrounding ambient air

\subsection{Laminar Flame Velocity}

Reactant velocity (v) is described in equation (3).

$v=\frac{Q_{\text {Fuel }}+Q_{\text {Air }}}{A_{b}}$

where: $Q$ fuel is volume flow rate of fuel, $Q$ air is volume flow rate of air, and $A_{b}$ is burner cross section area. Laminar flame speed $\left(\mathrm{S}_{\mathrm{L}}\right)$ can be estimated by using equation (4) as:

$S_{L}=v \cdot \sin \alpha$ 


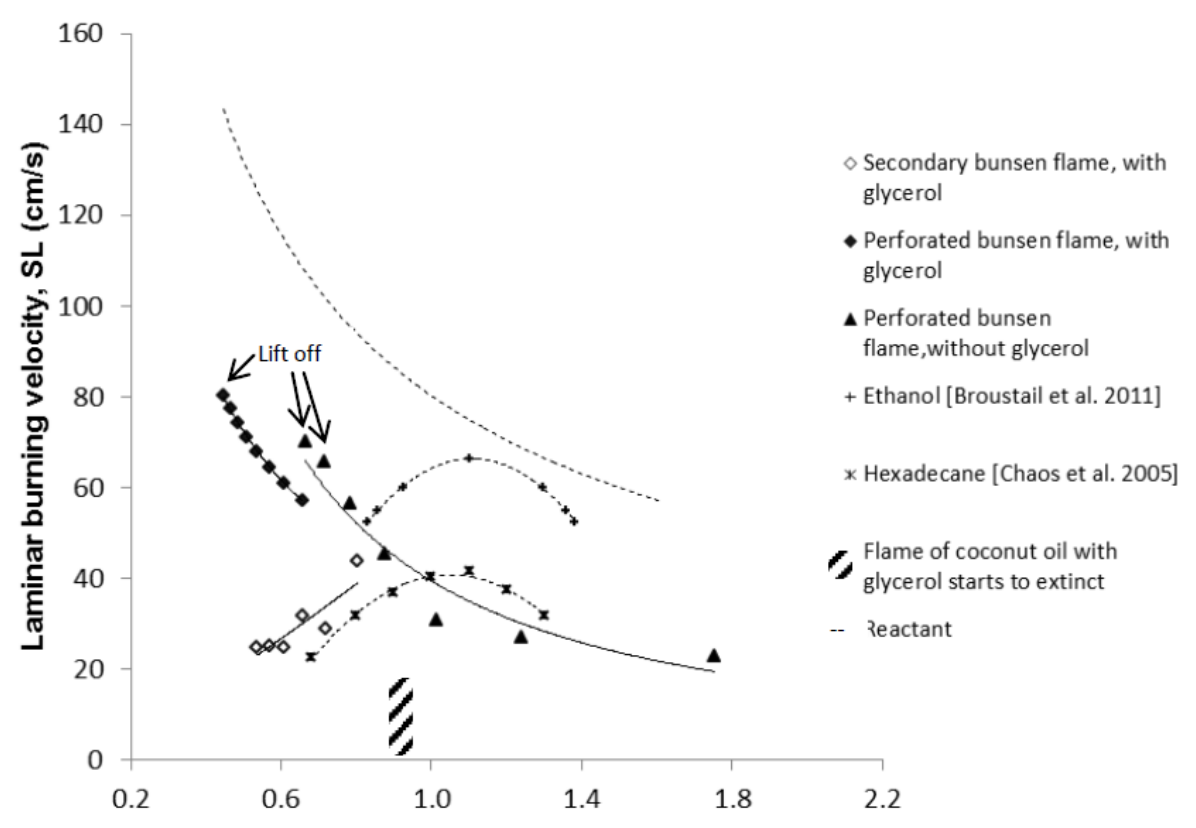

Fig. 8 Laminar burning velocity of coconut oil versus equivalence ratio isolated from ambient air

Fig.7 shows $S_{L}$ of coconut oil estimated from Fig.2 and Fig. 5 by using equation 4 . It is seen that $S_{L}$ of coconut oil perforated flame at very lean mixture almost equal as that of hexadecane flame at stoichiometry. As $\varphi$ is increased $\mathrm{S}_{\mathrm{L}}$ of perforated flame decreases and the flame started to disappears at $\varphi=$ 0.93. The secondary Bunsen flame takes place at the downstream of perforated flame from $\varphi=0.80$ with $S_{L}$ lower than that of perforated flame which also decrease with increasing $\varphi$. Without glycerol, perforated flame start to take place at a slightly larger $\varphi$ with $\mathrm{S}_{\mathrm{L}}$ became higher. Maximum $S_{L}$ still occurs at lean mixture that is higher than that of hexadecane (Chaos et al. 2005) but nearly the same as that of ethanol (Broustail et al. 2011). The $S_{L}$ tends to decrease with increasing $\varphi$. The flame is still stable even in the form of secondary Bunsen flame until the mixture is very rich. This shows that flammability limit of coconut oil is much wider than that of the conventional fossil fuel.

Fig. 8 shows $\mathrm{S}_{\mathrm{L}}$ of coconut oil estimated from Fig.4 and Fig. 6 . It can be seen at Fig. 8 that when the flame is isolated from ambient air the $S_{\mathrm{L}}$ of perforated flames reached the highest and even higher than that of ethanol (Broustail et al. 2011) at very lean mixture ( $\varphi$ $=0$. 45). As $\varphi$ is increased the $\mathrm{S}_{\mathrm{L}}$ decreases and the perforated flame disappear from $\varphi=0.66$ while the secondary Bunsen flame starts to take place at the downstream of perforated flame from $\varphi=0.54$ with $S_{\mathrm{L}}$ tends to increase following the trend of that of hexadecane (Chaos et al. 2005). The flame starts to extinct when $\varphi$ is nearly one or more. When the glycerol is removed from the oil the perforated flame start to form from $\varphi=0.72$ with $\mathrm{S}_{\mathrm{L}}$ higher than that with glycerol. The $\mathrm{S}_{\mathrm{L}}$ decreases with increasing $\varphi$. The flame is still stable in the form of perforated flame until the mixture become very rich $(\varphi=1.61)$. Again, this shows that glycerol need much air to burn so that it is stable at very lean mixture while fatty acids which are multicomponents is stable at higher $\varphi$ up to very reach mixture.

\subsection{Secondary Bunsen Flame with Open Tip}

At very lean mixture the number of air in the mixture is sufficient for complete combustion. $\mathrm{S}_{\mathrm{L}}$ is high and the Bunsen flame occurs on each hole of perforated nozzle. As $\varphi$ is increased the fraction of fuel in the mixture increases which absorb more energy for igniting the mixture. Consequently $\mathrm{S}_{\mathrm{L}}$ of longer-chain saturated fatty acids (palmitic and stearic acids) and glycerol is so low that results in secondary Bunsen flame in the downstream of perforted flame.

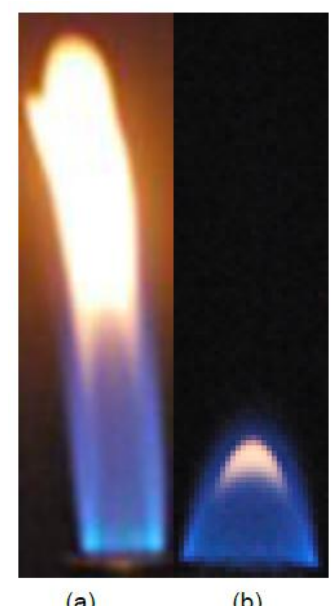

(a)

(b)

Fig. 9 Secondary Bunsen Flame Open Tip: (a) coconut oil with glycerol $\varphi=1.14$, (b) oil without glycerol $\varphi=1.24$ 
For $\mathrm{S}_{\mathrm{L}}$ is much lower than mixture velocity the secondary Bunsen flame tends to stretch which cause open tip. At higher $\varphi$ saturated longer-chain fatty acids and glycerol become difficult to burn and eventually escaped toward product zone to produce a yellow sooty diffusion flame in the tip of the flame. It is clearly seen from Fig. 9a that the open tip formation in the flame of coconut oil with glycerol at $\varphi=1.14$ is mainly caused by unburned glycerol that escapes into product zone. At coconut oil without glycerol (Fig. 9b) the open tip at $\varphi=$ 1.24 is caused by long chain saturated fatty acids. This indicates that glycerol needs more air to burn than longchain fatty acids. The open tip Bunsen flame mechanism made by both of escaped unburn fuel and pollutant is based on the Damkohler number concept (Ishizuka \& Sakai 1986).

\subsection{Cellular Flame}

Fig. 10 shows detailed structure of cellular flame of coconut oil with glycerol (Fig. 10a) and that of coconut oil without glycerol (Fig. 10b). Cellular flame occurs in unstable combustion process due to insufficient heat for burning of fuel, that is, in Lewis number (Le) much smaller than 1. In Fig. 10a cellular flame in combustion process of coconut oil with glycerol exists at rich mixture $(\varphi=1.14)$ where the number of air in the mixture is small not enough for burning of glycerol. Therefore, glycerol escapes to product zone becoming diffusion flame. Radiant heat from diffusion flame of glycerol serve heat energy for fast burning of mediumchain fatty acids (see Table 1) but it is not enough to burn the long-chain of fatty acid in the multi-component that compose the oil. This process results in island cellular flame on the perforated plate. This phenomenon is similar with that reported in Kadowaki et al. (2011). When glycerol is removed from the oil radiant heat from glycerol flame disappears. The long and medium chain fatty acids produce petals cellular flame in the Bunsen flame as shown in Fig. 10b. This result is similar with that discussed in Wang et al. (2009).

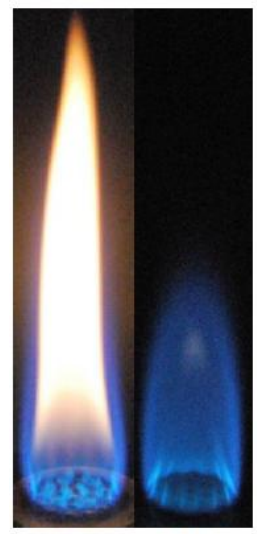
(a)
(b)

Fig.10 Cellular formation on (a) coconut oil with glycerol $\varphi=1.14$, (b) coconut oil without glycerol $\varphi=1.24$

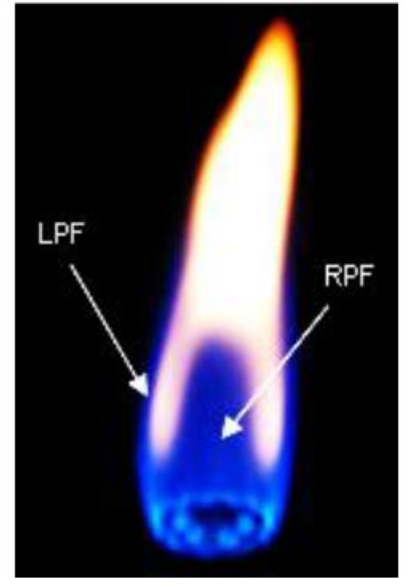

Fig.11 Form of coconut oil with glycerol flame at $\varphi=1.61$

\subsection{Triple Flame}

In Fig. 2 triple flame of coconut oil is formed at rich mixture from $\varphi=1.14$ to 1.61. Fig. 11 shows detail structure of triple flame of coconut oil with glycerol at $\varphi$ $=1.61$. The flame composed by rich premixed flame (RPF) at upstream region, diffusion flame in the middle, and lean premixed flame (LPF) in the downstream region. The structure comes from combustion process of coconut oil at rich mixture which produces rich premixed flame. Glycerol in coconut oil is difficult to be burnt at reaction zone since the air is not sufficient and it escapes to the product zone becoming diffusion flame. The diffusion flame both cannot expand from reaction zone because of fuel deficiency and cannot move toward reaction zone because of air deficiency. The inability of diffusion flame propagation causes free convection in the downstream region which pumps the cool air towards the reaction zone to meet and react with the rich premixed flame to produce lean premixed flame in the downstream region. Triple flame will be created by recirculation of hot gas free convection in lean premixed area or unsteady flame occur when hot gas travelling downstream as found by Jime'nez \& Cuenot (2007).

\section{Conclusion}

Coconut oil premixed combustion behavior has been studied experimentally on perforated burner with $\varphi$ varied from very lean until very rich. The results showed that at very lean mixture Bunsen flame is performed on every hole of perforated plate and their average laminar burning velocity reaches the highest, even it is higher than ethanol flame.

When $\varphi$ is increased the secondary Bunsen flame with open tip occurs from $\varphi=0.54$ at the downstream of perforated flame. Perforated flame speed decreases and it disappears at $\varphi=0.66$ while the secondary Bunsen flame velocity increased following that of hexadecane 
flame trend. The secondary Bunsen flame extincts when the equivalence ratio reaches one or more.

External air causes flame velocity decrease, shifts flame stable into richer mixture, and performs triple and cellular flames. The radiation heat energy from glycerol diffusion flame performs islands cellular flame on perforated hole.

Without glycerol, laminar flame velocity becomes higher and more stable as perforated flame at higher $\varphi$. At reach mixture the Bunsen flame becomes unstable and performs petal cellular flame.

\section{Acknowledgment}

This research is supported by The General Directorate of Higher Education (DIKTI) with contract number 175.35/UN14.2/PNL.01.03.00/2013 via Institute for Research and Community Services (LPPM), Udayana University Bali, Indonesia. The gratitude also gives to the Professor Takanobu Inoue from Toyohashi University of Technology.

\section{References}

Abdulwahid, M., Saqr, K. M., Sies, M.M. and Ujir, H. (2009) Diffusive thermal instabilities of $\mathrm{C}_{4} \mathrm{H}_{10}-\mathrm{C}_{3} \mathrm{H}_{8}$ /air laminar premixed flames. Diffusion-fundamentals.org, 9(8), 1-8.

Alamu, O.J., Dehinbo, O. and Sulaiman, A.M. (2010) Production and testing of coconut oil biodiesel fuel and its blend. Leonardo Journal of Sciences, 16, 95-104

Alenezi, R., Leeke, G.A., Santos, R.C.D. and Khan, A.R. (2009) Hydrolysis kinetics of sunflower oil under subcritical water conditions. Chemical Engineering Research and Design, 87, 867-873.

Ayhan, D. (2009) Progress and recent trends in biodiesel fuels. Energy Conversion and Management, 50, 14-34.

Benjapornkulaphong, S., Ngamcharussrivichai, C. and Bunyakiat K (2009) Al203-supported alkali and alkali earth metal oxides for transesterification of palm kernel oil and coconut oil. Chemical Engineering Journal, 145, 468-474.

Bouaid, A., Martínez, M. and Aracil, J. (2010) Biorefinery approach for coconut oil valorisation: A statistical study. Bioresource Technology, 101, 4006-4012.

Broustail, G., Seers, P., Halter, F., Moréac, G. and Mounaim-R.C. (2011) Experimental determination of laminar burning velocity for butanol and ethanol iso-octane blends. Fuel, 90, 1-6.

Chaos, M., Kazakov, A., Dryer, F.L., Zhao, Z. and Zeppieri, S.P. (2005) High temperature compact mechanism development for large alkanes: n-hexadecane. 6th International Conference on Chemical Kinetics.

Ishizuka S. And Sakai Y. (1986) Structure and tip-opening of laminar diffusion flames. Twenty-first Symposium (International) on Combustion/The Combustion Institute, 1821-1828.
Jime'nez , C. and Cuenot, B. (2007) DNS study of stabilization of turbulent triple flames by hot gases, Proceedings of the Combustion Institute, 31, 1649-1656.

Kadowaki, S., Takahashi, H. and Kobayashi H. (2011) The effects of radiation on the dynamic behavior of cellular premixed flames generated by intrinsic instability. Proceedings of the Combustion Institute, 33, 1153-1162.

Kratzeisen, M. and Müller, J. (2010) Influence of free fatty acid content of coconut oil on deposit and performance of plant oil pressure stoves. Fuel, 89, 1583-1589.

Kumar, G., Kumar, D., Singh, S., Kothari, S., Bhatt, S. and Singh C.P. (2010) Continuous low cost transesterification process for the production of coconut biodiesel. Energies, 3, 43-56.

Llamas, A, García-Martínez, M-J., Al-Lal, A-M., Canoira, L. and Lapuerta, M. (2012) Biokerosene from coconut and palm kernel oils: Production and properties of their blends with fossil kerosene. Fuel, 102, 483-490.

Machacon, H.T.C, Shiga, S., Karasawa, T. and Nakamura H. (2001) Performance and emission characteristics of a diesel engine fueled with coconut oil-diesel fuel blend. Biomass and Bioenergy, 20, 63-69.

Mizomoto, M. And Yoshida, H. (1987) Effects of Lewis number on the burning intensity of Bunsen flames. Combustion and Flame, 70, 47-60.

Palash, S.M., Kalam, M.A., Masjuki, H.H., Masum, B.M., Fattah, I.M.R. and Mofijur M. (2013) Impacts of biodiesel combustion on NOx emissions and their reduction approaches. Renewable and Sustainable Energy Reviews, 23, 473-490.

Qiao, L., Gan, Y., Nishiie, T., Dahm, W.J.A. and Oran, E.S. (2010) Extinction of premixed methane/air flames in microgravity by diluents: Effects of radiation and Lewis number. Combustion and Flame, 157, 1446-1455.

Recep, A., Selim, C. and Huseyin, S. (2001) The potential of using vegetable oil fuels as fuel for Diesel engine. Energy Conversion and Management, 42, 529-538.

Satyanarayana, M. and Muraleedharan, C. (2011) A comparative study of vegetable oil methyl esters (biodiesels). Energy, 36, 2129-2137.

Singh, P.J., Khurma, J. and Singh A. (2010) Preparation, characterization, engine performance and emission characteristics of coconut oil based hybrid fuels. Renewable Energy, 35, 2065-2070.

Suresh, R, Prasad, B.D, Raman, S.M. and Nibin T. (2009), Emission Control for a Glow Plug Direct Injection CI Engine Using Preheated Coconut Oil Blended Diesel. ARPN Journal of Engineering and Applied Sciences, 4 (8), 82-86

Vu, T.M., Park, J., Kim, J.S., Kwon, O.B., Yun, J.H., Keel, S.I. (2011) Experimental study on cellular instabilities in hydrocarbon/hydrogen/carbon monoxide-air premixed flames. International Journal of Hydrogen Energy, 36, 6914-6924.

Wang, W-C., Thapaliya, N., Campos A., Stikeleather, L. and Roberts, W.L. (2012) Hydrocarbon fuels from vegetable oils via hydrolysis and thermo-catalytic decarboxylation. Fuel, 95, 622-629.

Wang, Y., Hu, S. and Pitz, R.W. (2009) Extinction and cellular instability of premixed tubular flames. Proceedings of the Combustion Institute, 32, 1141-1147.

Wardana, I.N.G. (2010) Combustion characteristics of jatropha oil droplet at various oil temperatures. Fuel, 89, 659-664.

Yuan, W., Hansen, A.C. and Zhang Q. (2005) Vapor pressure and normal boiling point predictions for pure methyl esters and biodiesel fuels. Fuel, 84, 943-950. 